\title{
Analisis Penerapan Google Custom Search API pada Sistem Pencarian Data
}

\author{
Muhammad Nagib S. Hisam ${ }^{1}$, Ismail ${ }^{2}$ \\ ${ }^{1,2}$ Program Studi Informatika, Fakultas Teknik, Universitas Sulawesi Barat \\ ${ }^{1}$ nagib.s.hisam@gmail.com, ${ }^{2}$ ismailmajid@unsulbar.ac.id
}

\begin{abstract}
Abstrak
Sistem Pencarian merupakan aplikasi penting diterapkan pada sebuah media informasi online, namun sejak hadirnya mesin pencari seperti Google orang lebih suka menggunakan alat ini untuk menemukan informasi. Karena metode pencarian yang digunakan terbukti keandalannya. Apakah kita mampu seperti itu? Penelitian ini membuktikan bahwa dengan menerapkan metode Google Custom Search API, kita dapat membangun sistem pencarian layaknya seperti mesin pencari Google, hasil pengujian menunjukkan hasil pencarian yang ditampilkan sangat relevan dan rata-rata berada pada peringkat pertama. Keuntungan lainnya metode ini dilengkapi koreksi ejaan salah untuk menyempurnakan kata kunci sebenarnya.
\end{abstract}

Keyword: Google Custom Search API, AJAX, JSON Google, DOM

\begin{abstract}
Search system is an important application applied to an online information media, but since the presence of search engines like Google, people prefer to use this tool to find information. Because the search method used is proven to be reliable. Are we able to be like that? This research proves that by implementing the Google Custom Search API method, we can build a search system like Google's search engine, the test results show that the search results displayed are very relevant and on average are ranked first. Another advantage of this method is that it includes incorrect spelling corrections to perfect the actual keywords.
\end{abstract}

Keyword: Google Custom Search API, AJAX, JSON Google, DOM

\section{PENDAHULUAN}

Perkembangan teknologi memiliki banyak implikasi pada seluruh bidang kehidupan manusia, salah satunya pada perkembangan media informasi. Media informasi yang sedang banyak digandurungi orang adalah media informasi online seperti website atau aplikasi penyedia informasi secara online. Penggunaan media ini membantu menemukan berbagai informasi yang dibutuhkan. Data-data yang disediakan setiap media informasi online ada banyak dan beragam. Salah satu aplikasi penting diterapkannya dalam media informasi online adalah alat pencarian data, dengan alat ini pengguna mudah menemukan informasi sesuai yang diinginkan dari banyaknya data disediakan.

Menurut Perdananugraha (2013) banyak metode yang ditawarkan dalam mengembangkan alat pencarian, tapi perlu disadari sejak hadirnya mesin pencari seperti 
Google orang cenderung mengandalkan alat ini untuk menemukan informasi. Metode yang digunakan oleh mesin pencari telah terbukti keandalannya (Perdananugraha, 2013). Sehingga, pengguna lebih banyak menggunakan mesin pencari daripada fitur pencarian yang disediakan. Pertanyaan menarik adalah apakah kita dapat membuat fitur pencarian dengan metode seperti yang digunakan oleh mesin pencari Google.

Muslimah (2015) dalam penelitiannya membuktikan bahwa dari segi aspek kecepatan pencarian dan ketepatan hasil pencarian, pencarian berita menggunakan Google Custom Search API lebih cepat dan tepat dibanding menggunakan Web Crawler. Waktu proses rata-rata pencarian berita menggunakan Google Custom Search API lebih cepat kurang lebih 0,01 detik dan persentase ketepatan filtering isi artikel berita mencapai $88 \%$ (Muslimah, 2015). Penelitian tersebut membuktikan bahwa kita dapat membangun sistem pencarian seperti mesin pencari dengan menggunakan Google Custom Search API. Pada penelitian kali ini akan menganalisis bagaimana hasil penerapan Google Custom Search API pada sistem pencarian data yang dibangun. Data yang digunakan adalah data Badan Pusat Statistik Provinsi Sulawesi Barat.

\section{METODE PENELITIAN}

\subsection{Analisis Kebutuhan Data}

Menggunakan Google Custom Search API, kita dapat menggunakan data BPS tanpa mengumpulkan data dan membangun ulang database. Semua data yang dibutuhkan sudah tersedia di dalam database center Google. Google berhasil men-crawling data-data website diseluruh dunia termasuk website BPS. Data-data hasil crawling kemudian disimpan ke dalam database center milik Google. Crawling dilakukan secara rutin sehingga data yang tersimpan pun mengalami pembaharuan atau terupdate. Berikut adalah analisis untuk memenuhi kebutuhan data pada fitur pencarian yang akan dibangun.

Analisis Kebutuhan Data pada penelitian ini adalah sebagai berikut:

Sumber data
Metode akses data
Prasyarat
Ruang lingkup data
Jenis data
Link parsing JSON Google
(HTTP Request)
Keterangan

Sumber data

Metode akses data

Ruang lingkup data

(HTTP Req
Keterangan
Database Google Menggunakan layanan Google Custom Search API
API Key
Api_key
Id CSE
Id_cse

BPS Provinsi Sulawesi Barat (https://sulbar.bps.go.id) setting di www.google.com/cse

Berita Resmi Statistik (BRS), Publikasi dan Tabel Dinamis

https://www.googleapis.com/customsearch/v1?key=(Api_key)\&c

$\mathrm{x}=($ Id_cse $) \& \mathrm{q}=($ keyword $)$

: CSE (Custom Search Engine)

API (Application Programming Interface) 
Berdasarkan analisis awal, data yang diperoleh bersumber dari database Google yang diakses menggunakan Google Custom Search API. Adapun prasyaratan untuk menggunakan layanan API ini yaitu terdiri atas link website, API key, dan ID CSE. Link website dibutuhkan untuk perolehan data sesuai data situs diinginkan. API key dibutuhkan sebagai tiket untuk menggunakan layanan API Google. ID CSE dibutuhkan sebagai tiket untuk menggunakan Google Custom Search. Setelah ketiganya terpenuhi dengan baik, selanjutnya melakukan parsing dengan link parsing JSON Google.

\subsection{Analisis Kebutuhan Sistem}

Keberhasilan penerapan metode Google Custom Search API, sangat bergantung pada pemilihan parameter URL dan hasil parsing. Kedua jenis parameter tersebut adalah hal yang berbeda, dimana parameter URL digunakan untuk proses parsing, sedangkan parameter hasil parsing digunakan sebagai atribut menampilkan hasil pencarian. Berikut adalah analisis awal untuk memenuhi kebutuhan sistem pada fitur pencarian yang akan dibangun.

Tabel 1 Analisis Kebutuhan Sistem

\begin{tabular}{|c|c|c|}
\hline Komponen & Parameter & Spesifikasi \\
\hline $\begin{array}{l}\text { Parameter URL } \\
\text { HTTP Request } \\
\text { (https://www.googleapis.com/custom } \\
\text { search/v1?key=\{Api_Key? } \& \mathrm{cx}=\{\text { id } \\
\text { _cse? }\} \& \mathrm{q}=\{\text { keyword? }\} \& \text { start }=1 \text { ) }\end{array}$ & $\begin{array}{l}\text { cx } \\
\text { key } \\
\text { q } \\
\text { Start }\end{array}$ & $\begin{array}{l}\text { Merealisasikan Id CSE } \\
\text { Merealisasikan Kunci API } \\
\text { Merealisasikan kata kunci } \\
\text { Mengindeks hasil pertama, } \\
\text { digunakan mengatur pagination }\end{array}$ \\
\hline Parameter Hasil Parsing & $\begin{array}{l}\text { queries.request[].totalResults } \\
\text { items[].htmlTitle } \\
\text { items[].displayLink } \\
\text { data.items[].snippet } \\
\text { queries.nextPage[].startIndex } \\
\text { queries.request[].count }\end{array}$ & $\begin{array}{l}\text { Menampilkan kata kunci awal } \\
\text { atau yang dicari } \\
\text { Menampilkan kata kunci } \\
\text { dengan ejaan sesuai untuk } \\
\text { memperbaiki kata kunci ejaan } \\
\text { salah } \\
\text { Menampilkan total hasil } \\
\text { pencarian } \\
\text { Menampilkan judul konten } \\
\text { Menampilkan domain konten } \\
\text { Menampilkan deskripsi konten } \\
\text { Digunakan untuk mengakses } \\
\text { halaman selajutnya } \\
\text { Atribut pendukung kondisi }\end{array}$ \\
\hline
\end{tabular}

\subsection{Rancangan Sistem}

Pada penelitian ini sistem pencarian akan dikembangkan dengan metode Google Custom Search API. Sistem pencarian dibangun dengan beradaptasi HTTP request. Hasil dari HTTP request menampilkan parsing data dalam bahasa tipe JSON seperti yang ditunjukkan pada gambar 2.1. Selanjutnya menafsirkan data hasil parsing (gambar 1) kedalam bahasa HTML menggunakan metode AJAX (Asynchronous Javascript and XML). Atribut yang ditafsirkan adalah parameter hasil parsing (tabel 2). Tingkat keberhasilan penggunaan metode 
ini sangat bergantung pada rancangan struktur kode program. Kode program berhasil (gambar 2) merupakan revisi ke 20 menemukan rancangan kode program yang tepat untuk merealisasikan semua fungsi parameter terutama pada fungsi koreksi ejaan dan hasil pencarian.

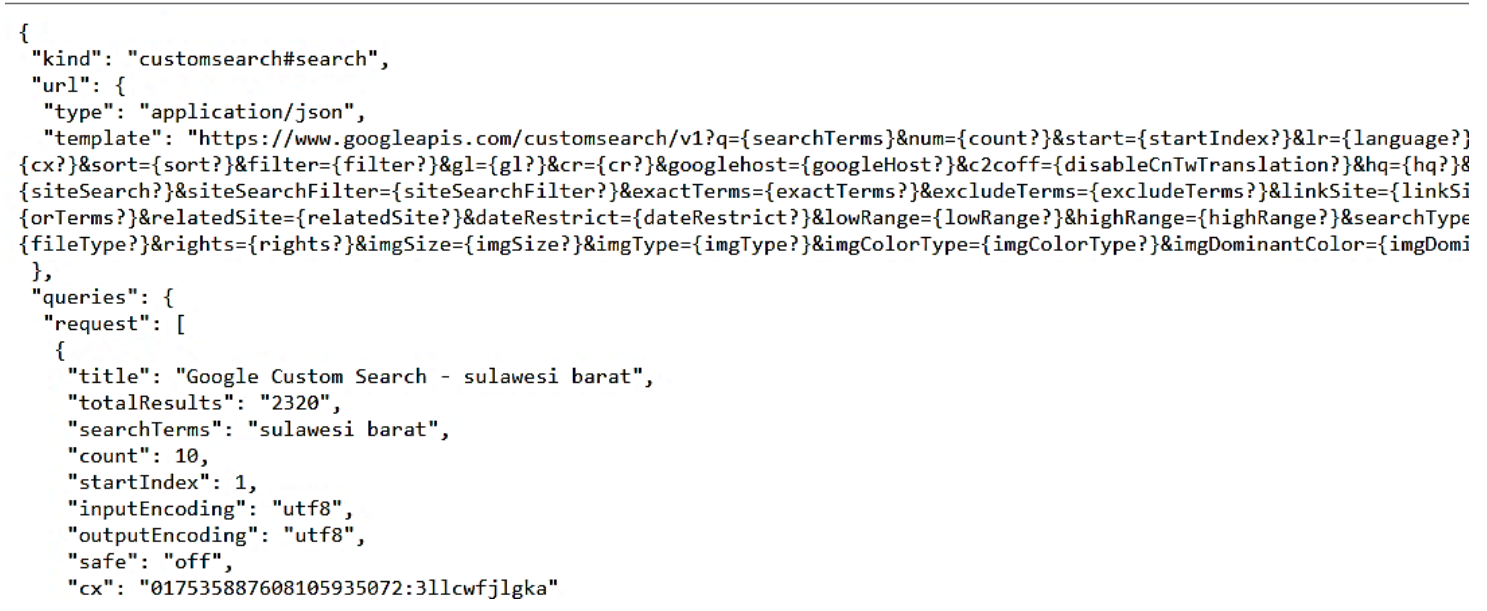

Gambar 1 Contoh Hasil Parsing HTTP Request JSON Google

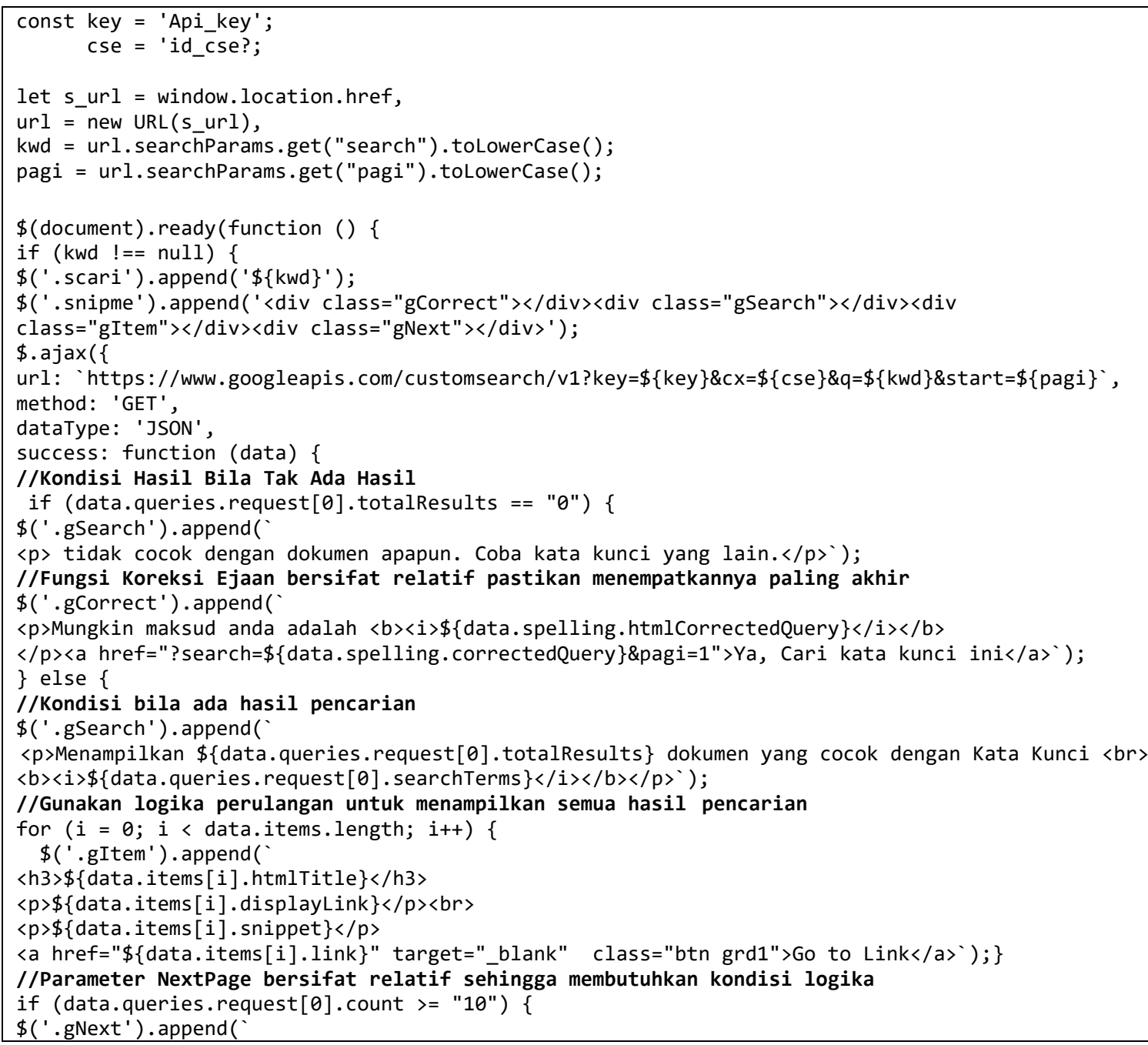




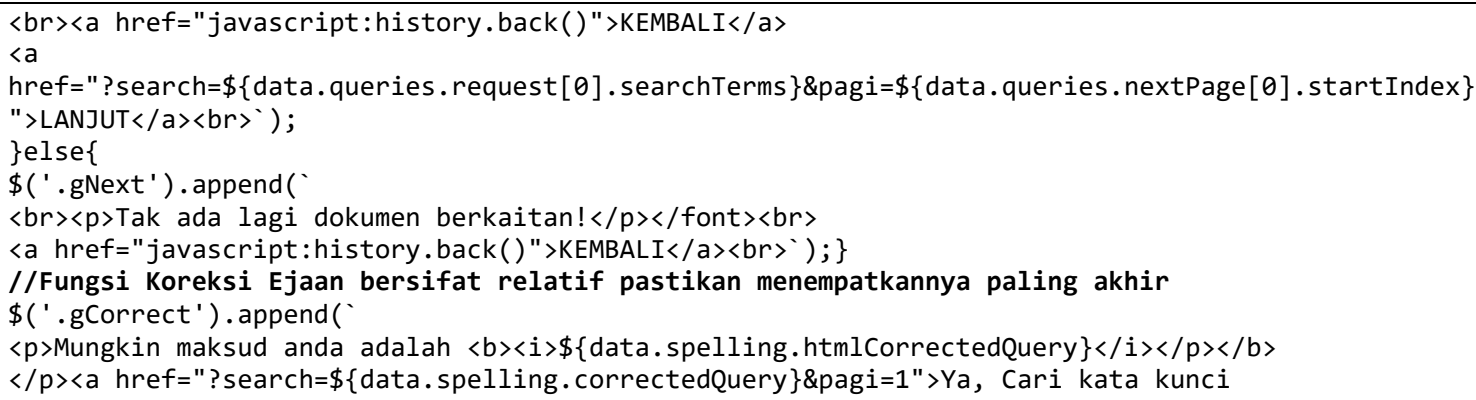

Gambar 2 Rancangan Kode Program

\subsection{Metode Pengujian}

Pada tahap ini dilakukan pengujian fungsional untuk menguji kinerja hasil penerapan metode Google Custom Search API. Pengujian ini berfokus pada fungsi parameter hasil pencarian dan koreksi ejaan. Fokus pengujian ini bertujuan untuk mengetahui seperti apa hasil yang ditampilkan apakah relevan atau tidak dan apakah benar ada koreksi ejaan.

\section{HASIL DAN PEMBAHASAN}

Setelah memenuhi semua prosedur penelitian sistem dibuat menjadi library Javascript menggunakan metode HTML DOM (Document Object Model), dapat digunakan pada sistem berbasis HTML. Berikut adalah hasil penerapan Google Custom Search API.

\subsection{Sistem mampu melakukan proses dan menampilkan hasil pencarian}
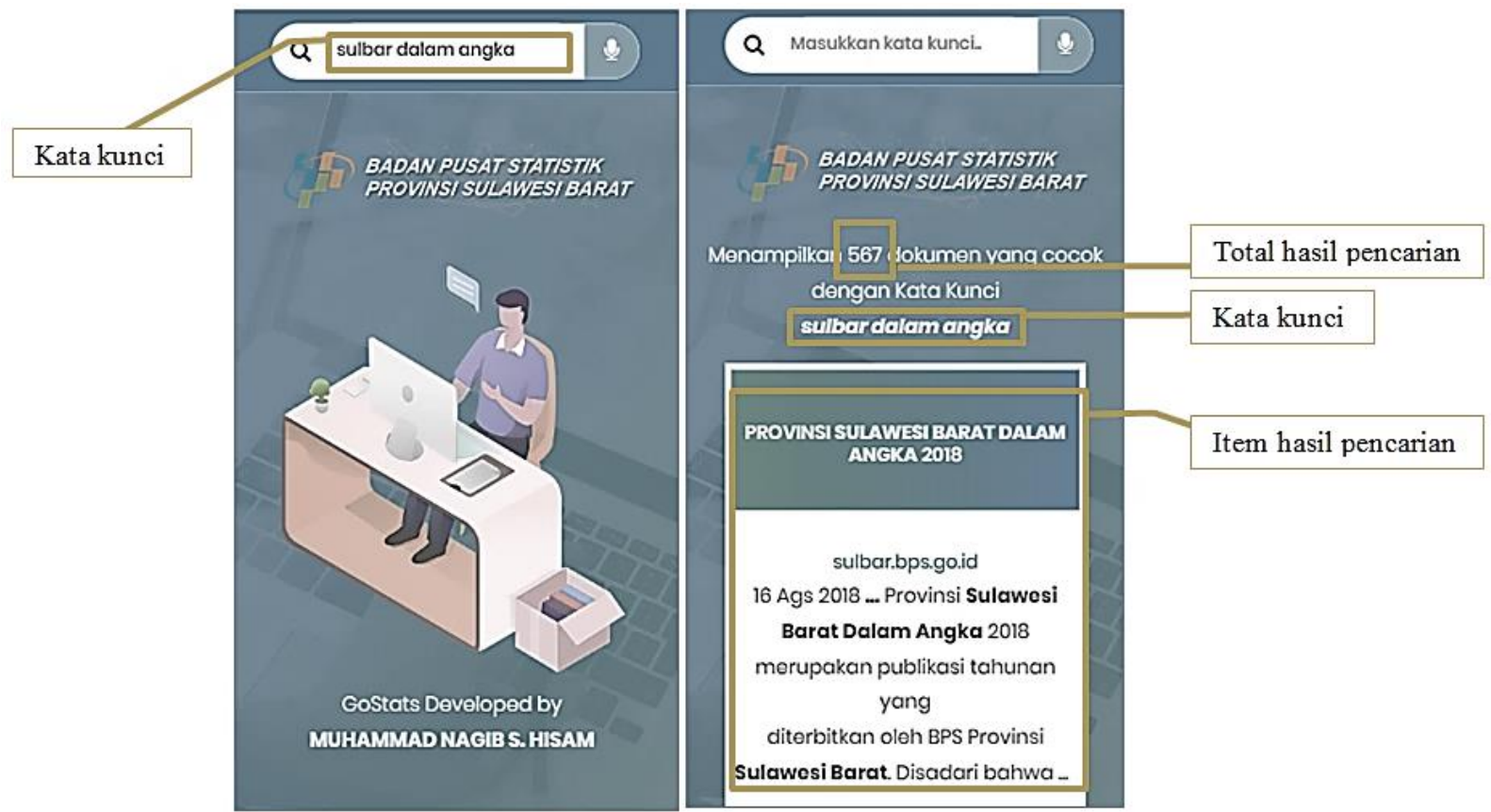

Gambar 3. Hasil Testing Hasil Sistem Pencarian 


\subsection{Sistem mampu mengoreksi kata ejaan salah}
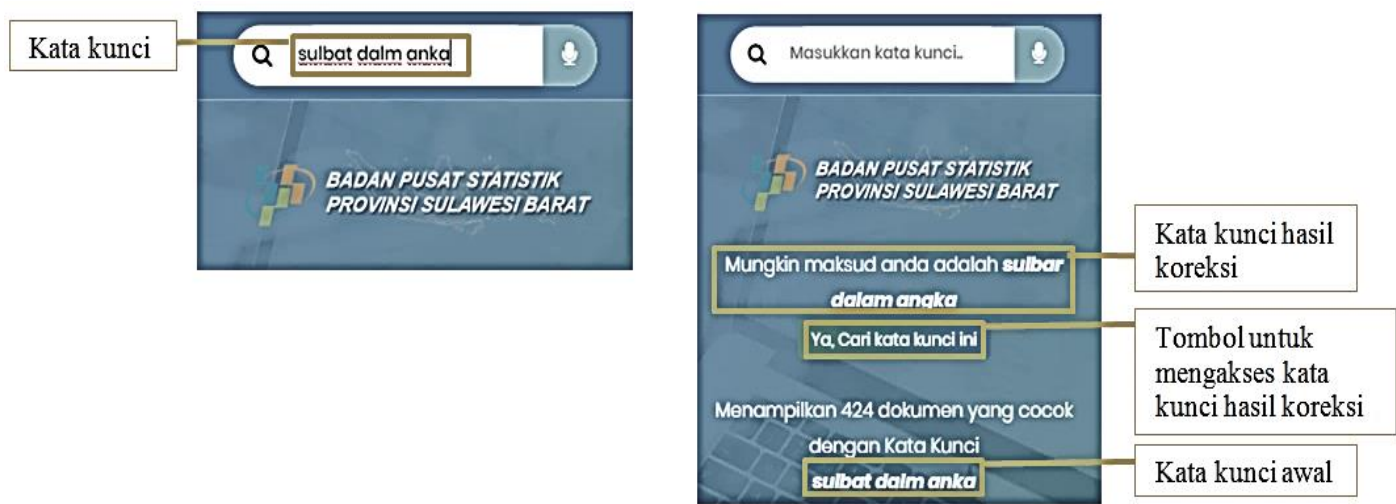

Gambar 4. Hasil Testing Koreksi Kata Salah Ejaan

\subsection{Pembahasan}

Berdasarkan hasil pengujian sistem dengan menerapkan metode pencarian menggunakan metode Google Custom Search API. Sistem mampu melakukan proses dan menampilkan hasil pencarian. Hasil yang ditampilkan paling relevan rata-rata berada pada peringkat pertama (tabel 2). Keuntungan lainnya seperti yang ditunjukkan pada gambar 4, dimana sistem mampu mengoreksi kata ejaan yang salah dan merekomendasikan kata dengan ejaan yang sesuai.

Tabel 2. Hasil Evaluasi Uji Pengguna

\begin{tabular}{clllc}
\hline No. & \multicolumn{1}{c}{ Nama } & Pekerjaan & \multicolumn{1}{c}{ Kata Kunci } & $\begin{array}{c}\text { Hasil Pada } \\
\text { Peringkat }\end{array}$ \\
\hline 1. & DHANI SETYO & PNS & Jumlah Penduduk & 1 \\
2. & EVA & PNS & Inflasi Kab. Polewali Mandar & 1 \\
3. & SRI KRISKANI & PNS & Jumlah Penduduk & 1 \\
4. & SYUKUR M.M. & PNS & Kesejahteraan Rakyat Miskin & 1 \\
5. & AAN & PNS & Gini Rasio, Inflasi & 1 \\
6. & HARLINA & PNS & Inflasi 2019, Penduduk & 1 \\
7. & HARYO SATRRAJI & PNS & Penduduk & 4 \\
8. & AMALIA & PNS & Inflasi September & 2 \\
& TANGDILAMBI & & & 2 \\
9. & BUNTORO S.ST & PNS & Inflasi,Pengangguran, Partisipasi & \\
& & & Murni, IPM, Indikator Strategis, Sawit, & \\
& & & Hotel Bintang, Susenas, IHK, Rumah \\
& & Tangga Miskin, Rasio Gini, Gini Rasio & \\
10. & KASIFUL & PNS & 2019, Tabel Penduduk 2018 & \\
& APRIANTO & & Demokrasi 2019, Sawit 2019 & 1 \\
11. & SRI MULYANI & PNS & Kemiskinan & 1 \\
& S.ST., MM & & & \\
\hline
\end{tabular}




\section{KESIMPULAN}

Berdasarkan hasil penelitian dan pembahasan yang telah diuraikan diatas, dapat disimpulkan bahwa dengan menggunakan metode Google Custom Search API, kita dapat membangun sistem pencarian dengan kehandalan tinggi layaknya seperti mesin pencari Google. Rata-rata hasil pencarian yang ditampilkan sangat relevan dan berada pada peringkat pertama. Selain itu, keuntungan menggunakan metode ini dilengkapi fitur koreksi ejaan dan merekomendasikan ejaan yang sesuai. Fitur koreksi ini sangat membantu pengguna untuk menyempurnakan kata kunci yang diinginkan. Kelemahan sistem ini hasil yang ditampilkan memang relevan, namun belum benar-benar update. Untuk mendapatkan hasil yang update pengguna harus menambahkan kata kunci tahun 2019.

\section{REFERENSI}

[1] Muslimah, Z. N. 2015. Aplikasi Pencarian Berita Untuk Media Monitoring dengan MenggunakanWeb Crawler dan Google Custom Search API. Skripsi. Yogyakarta: Fakultas Matematika dan Ilmu Pengetahuan Universitas Gadjah Mada Yogyakarta

[2] Allauddin, M dan Azam, F. 2011. Service Crawling using Google Custom Search API (Online), Vol.34 No.7 (https://pdfs.semanticscholar.org/59e7 le6651692ef08d60e4de469b92d065dd0dd54.pdf, di akses 4 September 2019)

[3] Perdananugraha. 2013. Utilization of Google's Custom Search in Knowledge Finding on Digital Library (Online), Vol.13 No.02 (http://ijens.org/Vol_13_I_02/135402-8686-IJECS-IJENS.pdf, di akses 4 September 2019)

[4] Arkan, L. 2018. Perilaku Pencarian Informasi Menggunakan Search Engine Google oleh Mahasiswa Prodi S1 Ilmu Perpustakaan Angkatan 2015 Terhadap Model Ellis. Skripsi. Darusalam-Banda Aceh: Fakultas Adab dan Humaniora Universitas Islam Negeri Ar-Raniry Darusalam-Banda Aceh

[5] Ariyanti, C. V. 2016. Pengaruh Penggunaan Google Search Engine dalam Pemenuhan Kebutuhan Informasi di Kalangan Mahasiswa (Studi pada Mahasiswa Program Studi S1 Fakultas Ekonomi dan Bisnis Universitas Lampung). Skripsi. Bandar Lampung: Fakultas Ilmu Sosial dan Ilmu Politik Universitas Lampung

[6] Kurniadi, D. dan Mulyani, A. 2017. Pengaruh Teknologi Mesin Pencari Google Terhadap Perkembangan Budaya dan Etika Mahasiswa (Online), Vol.14 No.1 (https://www.researchgate.net/publication/317579221_Pengaruh_Teknologi_Mesin_Pe ncari_Google_Terhadap_Perkembangan_Budaya_dan_Etika_Mahasiswa, di akses 6 September 2019) 